Archives

\title{
Introduction - Rapport d'étape
}

Christophe Blanquie, Michel Cassan et Robert Descimon

\section{Q OpenEdition \\ Journals}

\section{Édition électronique}

URL : http://journals.openedition.org/ccrh/2302

DOI : $10.4000 /$ ccrh.2302

ISSN : $1760-7906$

\section{Éditeur}

Centre de recherches historiques - EHESS

\section{Édition imprimée}

Date de publication : 20 octobre 1999

ISSN : 0990-9141

\section{Référence électronique}

Christophe Blanquie, Michel Cassan et Robert Descimon, «Introduction - Rapport d'étape », Les Cahiers du Centre de Recherches Historiques [En ligne], 23 | 1999, mis en ligne le 17 janvier 2009, consulté le 10 décembre 2020. URL : http://journals.openedition.org/ccrh/2302 ; DOI : https://doi.org/ $10.4000 /$ ccrh. 2302

Ce document a été généré automatiquement le 10 décembre 2020.

Article L.111-1 du Code de la propriété intellectuelle. 


\title{
Introduction - Rapport d'étape
}

\author{
Christophe Blanquie, Michel Cassan et Robert Descimon
}

1 Deux objectifs présidèrent à l'organisation de la table ronde « Présidiaux, élections... : le travail des institutions ", tenue à Paris les 28 et 29 mai 1999 et dont les Cahiers du Centre de recherches historiques publient déjà les actes.

2 Le premier et le plus évident était de donner une suite au colloque de Limoges ${ }^{1}$ et de le doubler d'un élargissement thématique. Le second était d'envisager la création d'un groupe de recherche et de décider des modalités d'une demande de reconnaissance auprès des institutions de tutelle (MENRT, CNRS).

3 Sur le premier point, la question proposée visait à mieux connaître les pratiques et les techniques professionnelles des magistrats et des officiers de finance exerçant dans des élections, des maîtrises des eaux et forêts, des greniers à sel. En filigrane, il s'agissait de réfléchir à la professionnalisation de ces administrateurs, ses infléchissements éventuels au cours des $\mathrm{XVI}^{\mathrm{e}}$ et $\mathrm{XVII}^{\mathrm{e}}$ siècles et de confronter les conclusions aux réflexions menées depuis quelques années sur la genèse de l'État "moderne ». Ce programme, peut-être prématuré, reste encore à défricher, tant il est vite apparu aux contribuants combien l'analyse de l'exercice quotidien du travail de l'institution et de ses membres se révélait délicate voire austère. L'étalonnage d'une modernisation des techniques professionnelles reste insuffisamment étudié pour qu'une norme acceptable et pertinente puisse être dégagée. Toutefois, cette piste de recherche semble prometteuse et elle peut déjà être adossée aux modifications formelles et intellectuelles qui caractérisent le travail des bureaux des intendances au xviii ${ }^{e}$ siècle. Il y a là une référence à l'aune de laquelle on peut, dans un premier temps, évaluer l'activité professionnelle des officiers «moyens ». Elle permettra de déterminer si des techniques nouvelles pénétrèrent l'univers des juges et des élus ou si les magistrats demeurèrent imperméables, rétifs à toute transformation et pérennisèrent une tradition vénérable patinée par la coutume.

4 La crise des présidiaux ou, pour user d'un terme moins galvaudé et flou, leur dépérissement, reste un champ d'investigation fondamental. L'historiographie des XIX et $\mathrm{Xx}^{\mathrm{e}}$ siècles martèle la thèse du déclin des présidiaux au XVIII ${ }^{\mathrm{e}}$ siècle. Elle a épousé la thèse des juges et de Daniel Jousse, leur député auprès de la chancellerie et du Conseil, mais sans avancer de données chiffrées susceptibles d'étayer l'affirmation. Une première série 
de réponses est ici apportée qu'il conviendra d'affiner en intégrant les autres activités des magistrats pour prendre la pleine mesure de leur labeur et disposer de résultats encore plus solides. Des premiers jalons ont été posés et d'autres analyses monographiques devront suivre, dans une démarche comparative indispensable et, à amplifier.

Le monde des officiers naturalisés «moyens » par Jean Nagle en raison de leur position intermédiaire dans les organigrammes et les tarifs de taxation dressés par la monarchie aux $\mathrm{XVI}^{\mathrm{e}}-\mathrm{XVIII}^{\mathrm{e}}$ siècles reste très peu et mal connu; or ce groupe étoffé, composé d'hommes qui sont souvent les premiers dans maintes cités de province, a rempli un rôle que l'on pressent décisif dans l'histoire de l'État et des villes. Il a participé à la Réforme catholique, il a animé les cercles de la sociabilité savante et érudite provinciale et exercé un magistère sur les innombrables villes de taille moyenne du royaume.

6 Ces multiples facettes des officiers "moyens", leur inscription dans l'histoire des institutions, de l'État, de la ville, des idées, ont été évoquées les 28 et 29 mai lors de débats et de discussions qu'il était impossible de retranscrire. Et au terme de la réunion, il a été décidé de poursuivre l'enquête. Une demande de GDR a été décidée, à laquelle se sont associés plusieurs centres de recherche dont le Centre de recherches historiques. Le dossier de GDR intitulé Le Monde des officiers « moyens » en France du XVe siècle au début du XIX e siècle a été déposé, avec la faculté des lettres et sciences humaines de Limoges comme adresse administrative.

\section{NOTES}

1. Michel Cassan, éd., Les Officiers «moyens » à l'époque moderne : pouvoir, culture, identité, actes du colloque de Limoges, Pulim, 1998, 399 p. 